\title{
Comparative Toxicity of Certain Insecticides against Two Species of Fruit Flies Safaa M. Halawa ${ }^{1}$; E. F. El-Khiat ${ }^{1}$; Rasha A. El-Hosary ${ }^{1}$; Maha M. S. Ismail ${ }^{2}$ and A. M. Z. Mosallam ${ }^{2}$ \\ ${ }^{1}$ Plant Protection Department, Fac. of Agric., Moshtohor, Benha Univ. \\ ${ }^{2}$ Plant Protection Research Institute, Dokki, Giza, Egypt
}

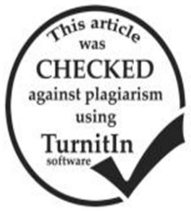

ABSTRACT

The full grown larvae and pupae of 3-days old of both Bactrocera zonata and Ceratitis capitata were sandy-soil-treated under laboratory conditions with five different insecticides to determine their comparative toxicity. The toxicity of the used compounds differently varied against the $3^{\text {rd }}$ larval instar of B. zonata, where Marisol $1.8 \%$ EC (abamectin) surpassed the other tested compounds at $\operatorname{LC}_{50}\left(5.343 \mu \mathrm{l} / \mathrm{L}\right.$ ), while Opal 5\%EC (lufenuron) was the most effective insecticide against the $3^{\text {rd }}$ larval instar of $C$. capitata showing the lowest value of $\mathrm{LC}_{50}$ of $11.299 \mu \mathrm{l} / \mathrm{L}$. Respecting to the three-day old pupae of the two tested species, Marisol $1.8 \% \mathrm{EC}$ was the most potent compound at $\mathrm{LC}_{50}(395.461 \mu \mathrm{1} / \mathrm{L}$ for $B$. zonata and $151.373 \mu \mathrm{1} / \mathrm{L}$ for $C$. capitate). The full grown larvae of $B$. zonata were the most susceptible to Heater $3 \% \mathrm{SC}$ (lufenuron+emamectin benzoate) and Marisol $1.8 \% \mathrm{EC}$ at both $\mathrm{LC}_{50}$ and $\mathrm{LC}_{90}$, where those of $C$. capitata showed tolerance level to the two insecticides by $7.78,14.16$ and $6.02,8.47$ fold at $\mathrm{LC}_{50}$ and $\mathrm{LC}_{90}$, respectively. But, pupae of B. zonata more tolerable than that of $C$. capitate to Glory $5 \% \mathrm{EC}$ (lufenuron), Marisol $1.8 \% \mathrm{EC}$ and Cymax $5 \% \mathrm{EC}$ (lufenuron) at $\mathrm{LC}_{50}$ and $\mathrm{LC}_{90}$ by $5.54,2.61,1.87$ and $8.29,2.32,3.28$ fold, respectively.

Keywords: Insecticide, Fruit flies, Bactrocera zonata, Ceratitis capitata, Toxicity.

\section{INTRODUCTION}

Fruits and vegetables provide essential nutritional elements of the consumer body. Fruits are very much attractive for human being, they offer a variety of delicious tastes and many of them like guava, mangoes, peaches, papaya etc. have great visual appeals. Unfortunately, the fruit growing areas favor the activities of many insect pests. Among the insect pests of fruit and vegetable crops, fruit flies are of special importance (Jilani et al., 2006). Fruit flies (Diptera: Tephritidae) distributed all over the world and considered deleterious insect-pests of horticultural crops. There are nearly 5,000 described species of tephritid fruit flies, categorized in almost 500 genera, of which about 70 species are economically very important. The genera Bactrocera and Ceratitis have a world-wide reputation for its destructive impact on agriculture (Lysandrou, 2009). In Arab countries, fruit flies have become severe regional problems, with many fruit flies of economic importance. The most notable are the Mediterranean fruit fly, C. capitita (Wied.), peach fruit fly, B. zonata (Saund.), olive fruit fly, B. oleae (Gmelin) and others (Lysandrou, 2009). The peach fruit fly, B. zonata is recognized as one major insect pest attacking fruits and vegetables. This pest spread in many regions of the world (Drew, 1989). This tephirtid fly occurs in south east Asia, India, Mauritius, Pakistan, Reunion island, Serilanka, Thailand, Vietnam and Indonesia. In Middle East regions, it established and widespread in Egypt and also presented in Yemen, Iran, Saudi Arabia, United Arab Emirates and Oman. It has been recently reported in Palestine and Lebanon (FAO/IAEA, 2000) when not treated. The peach fruit fly can affect the entire yield of horticultural crops. The Mediterranean fruit fly or med-fly, C. capitata is a multivoltine and polyphagous insect-pest that limits the development and expansion of fruit agriculture in many localities in subtropical and temperate regions, since this insect has a high biotic potential and a wide range host. $C$. capitata is a dangerous agricultural pest in EuropeanMediterranean basin, South Africa, central and South America, South Western Australia, Hawaii and USA i.e., the medfly is a cosmopolitan pest that has a wide host range of over 250 species of fruit trees, nut and vegetable plants (McDonald, 1986). Generally, the Integrated Pest Management (IPM) programs for fruit flies rely mainly on insecticides as coverage or partial-bait spray, soil-drench treatments, male annihilation technique and poisoned mass trapping methods (Saul and \& Seifert, 1990; Mohamed \& El-Nasser, 1992; Stark et al., 1992; Mosallam, 1993; Purcell \& Schroeder, 1996; Abdallahi et al. 2000; Stark \& Vargas, 2009; Rizwanual Haq et al., 2012; Halawa et al., 2013 and Stark et al., 2014).

Thus, this work aimed to study toxicity and comparative potency of certain pesticides against two immature or developmental stages (the $3^{\text {rd }}$ instar larvae and pupae of 3-day old) of the two species of fruit flies $B$. zonata and $C$. capitata in sand under laboratory conditions.

\section{MATERIALS AND METHODS}

\section{1- Rearing Technique}

Full grown larvae and pupae of Bactrocera zonata and Ceratitis capitata were obtained from strains continuously reared in the laboratory of Horticulture Insects Department, Plant Protection Research Institute, Agricultural Research Center, Dokki, Giza under conditions of $25 \pm 3^{\circ} \mathrm{C}$ and $60 \pm 5 \%$ R.H. Adults of both $B$. zonata and $C$. capitata were reared in a wooden cage (40x40x40cm) which covered from all sides with metal screen, but the cage of $C$. capitata was covered from a side with muslin cloth for ovipositing, where eggs were collected in a metal pan $(40 \times 10 \times 5 \mathrm{~cm})$. Adults of the two species were fed with sugar mixed with fortified protein hydrolysate at ratio of $3: 1$, respectively. Also, water was added in plastic bottles. The cage of B. zonata was supplied with false plastic fruits that had many fine pores (as oviposition receptacles). These plastic fruits are filled with $3 \mathrm{~cm}$ water to receive and prevent drying of the eggs. Larvae of both species were reared on an artificial diet (500 $\mathrm{ml}$ tap water, $3.00 \mathrm{gm}$ sodium benzoate, $3.00 \mathrm{gm}$ citric acid, $84.50 \mathrm{gm}$ sugar, $84.50 \mathrm{gm}$ brewer's yeast and $330 \mathrm{gm}$ wheat bran). These ingredients were carefully mixed in a large plastic container. Then eggs were scattered on the surface of the diet which was placed in plastic trays of $20 \times 10 \times 8 \mathrm{~cm}$ tightly covered with muslin clothes using rubber bands. After that, these trays were placed in a large plastic van with sand at the bottom to allow the jumping larvae to 
pupate. All pupae were separated by sieving from sand (Shehata et al., 2006).

\section{2- Pesticides Used}

Three types of formulations of the Insect Growth Regulators (IGRs) lufenuron and a neonicotinoid compound of abamectin as well as a mixture of lufenuron and emamectin benzoate were comparatively evaluated as toxic agents against two immature stages (the full grown larvae and pupae of 3-day old) of both $B$. zonata and $C$. capitata. These used compounds were shown in the following table:

\begin{tabular}{lccc}
\hline Trade name & Common name & Producer & Rate of use \\
Cymax 5\% EC & lufenuron & $\begin{array}{c}\text { Zhejiang Sega Science and } \\
\text { Technology Co., Ltd, China }\end{array}$ & $\begin{array}{c}40 \mathrm{ml} / 100 \mathrm{~L} \text { water for grapevine } \\
\text { moth on grapes }\end{array}$ \\
\hline Glory 5\% EC & lufenuron & Medmac Company in Jordan & $\begin{array}{c}40 \mathrm{ml} / 100 \mathrm{~L} \text { water for grapevine } \\
\text { moth on grapes }\end{array}$ \\
\hline Heater 3\% SC & $\begin{array}{c}\text { 2\% lufenuron + 1\% } \\
\text { emamectin benzoate }\end{array}$ & $\begin{array}{c}\text { Zhejiang Sega Science and } \\
\text { Technology Co., Ltd, China }\end{array}$ & $\begin{array}{c}40 \mathrm{ml} / 100 \mathrm{~L} \text { water for grapevine } \\
\text { moth on grapes }\end{array}$ \\
\hline Marisol 1.8\% EC & abamectin & Industerial Quimica KEY S.A., Spain & $\begin{array}{c}40 \mathrm{ml} / 100 \mathrm{~L} \text { water for red mite on } \\
\text { grapes }\end{array}$ \\
\hline Opal 5\% EC & lufenuron & Jiangsu Flag Chemical Industry Co., & $\begin{array}{c}40 \mathrm{ml} / 100 \mathrm{~L} \text { water for grapevine } \\
\text { moth on grapes }\end{array}$ \\
\hline
\end{tabular}

\section{3- Bioassay Tests}

The efficacy of the tested toxicants was evaluated in sand against the full grown larvae and 3-day old pupae of both B. zonata and C. capitata. Sand was sieved and put in plastic cups $(100 \mathrm{gm} / \mathrm{each})$. Twenty to thirty full grown larvae or 3-day old pupae were confined and buried into sand in each cup. A series of gradual concentrations in tap water of each compound for each stage of each species were used. Then, ten milliliters (required amount for saturation) of each concentration were added per each cup. Then, cups were covered with muslin clothes that tightly secured with rubber bands and left under the above mentioned laboratory conditions till adult emergence. For each concentration, three replicates were used. Control individuals were treated with water only for comparison and correcting mortalities.

\section{4- Statistical Analysis}

The observed mortality was corrected with Abbott's formula (Abbott, 1925) and plotted against concentrations as $\log$ /probit regression lines. $\mathrm{LC}_{50}$ and $\mathrm{LC}_{90}$ values as well as the slope of the toxicity lines were calculated using Ld-p Line ${ }^{\circledR}$ software. [http://embakr. tripod.com/ldpline/ldpline.htm]. Toxicity index was obtained by comparing the efficiency of different insecticides at $\mathrm{LC}_{50}$ and $\mathrm{LC}_{90}$ with that of the highly potent compound according to the equation of Sun (1950)

\section{RESULTS}

\section{1- Toxicity Against the Full Grown Larvae Toxicity against $B$. zonata}

The obtained results compiled in Table (1) and Figure (1) show the toxicity of certain insecticides against the $3^{\text {rd }}$ larval instar of $B$. zonata in sand under laboratory conditions. Marisol 1.8\%EC surpassed the other tested compounds at both $\mathrm{LC}_{50}$ and $\mathrm{LC}_{90}(5.343$ and $20.011 \mu \mathrm{l} / \mathrm{L}$, respectively). The other tested pesticides arranged descendingly, according to $\mathrm{LC}_{50}$ values, as Heater $3 \% \mathrm{SC}$ $(17.261 \mu \mathrm{l} / \mathrm{L})$, Opal 5\%EC $(196.998 \mu \mathrm{l} / \mathrm{L})$, Glory 5\%EC $(368.719 \mu \mathrm{l} / \mathrm{L})$ and Cymax 5\%EC (443.796 $\mu \mathrm{l} / \mathrm{L})$. But, according to $\mathrm{LC}_{90}$, the descending arrangement of toxicity was as follow, Heater 3\% SC, Opal 5\%EC, Cymax 5\%EC and Glory $5 \% \mathrm{EC}$ that recorded $\mathrm{LC}_{90}$ values of 91.046 , 919.546, 2495.620 and $2790.899 \mu \mathrm{l} / \mathrm{L}$, respectively. Respecting slope values of toxicity lines of the used compounds, Marisol 1.8\% showed the steepest LC-p line (2.235). The toxicity lines of both Heater $3 \% \mathrm{SC}$ and
Cymax 5\%EC were nearly paralleled recording slope values of 1.775 and 1.709 , respectively. The toxicity line of Glory $5 \% \mathrm{EC}$ was the flattest (1.458). Regarding toxicity index, Marisol 1.8\% was the standard showing the most efficiency against the $3^{\text {rd }}$ instar larvae of $B$. zonata at both $\mathrm{LC}_{50}$ and $\mathrm{LC}_{90}$. Efficiency of the other tested compounds was $1.45,30.95,2.71$ and $1.20 \%$ of the standard insecticide at $\mathrm{LC}_{50}$, but it was $0.72,21.98,2.18$ and $0.80 \%$ of Marisol $1.8 \% \mathrm{EC}$ at $\mathrm{LC}_{90}$ for Glory $5 \% \mathrm{EC}$, Heater $3 \% \mathrm{SC}$, Opal 5\%EC and Cymax 5\%EC, consecutively.

Table 1. Toxicity of certain insecticides against the full grown larvae of $B$. zonata in sand.

\begin{tabular}{lcccccc}
\hline \multirow{2}{*}{ Compound } & \multirow{2}{*}{$\begin{array}{c}\mathbf{L C}_{\mathbf{5 0}} \\
(\boldsymbol{\mu l} / \mathbf{L})\end{array}$} & $\begin{array}{c}\mathbf{L C}_{\mathbf{9 0}} \\
(\boldsymbol{\mu} \mathbf{l} / \mathbf{L})\end{array}$ & Slope & \multicolumn{3}{c}{$\begin{array}{c}\text { Toxicity } \\
\text { index at }\end{array}$} \\
\cline { 6 - 7 } & & & & $\mathbf{L C}_{\mathbf{5 0}}$ & $\mathbf{L C}_{\mathbf{9 0}}$ \\
\hline Cymax 5\%EC & 443.796 & 2495.620 & $1.709 \pm 0.128$ & 1.20 & 0.80 \\
Glory 5\%EC & 368.719 & 2790.899 & $1.458 \pm 0.301$ & 1.45 & 0.72 \\
Heater 3\%SC & 17.261 & 91.046 & $1.775 \pm 0.276$ & 30.95 & 21.98 \\
Marisol1.8\%EC & 5.343 & 20.011 & $2.235 \pm 0.325$ & 100 & 100 \\
Opal 5\%EC & 196.999 & 919.546 & $1.916 \pm 0.152$ & 2.71 & 2.18 \\
\hline
\end{tabular}

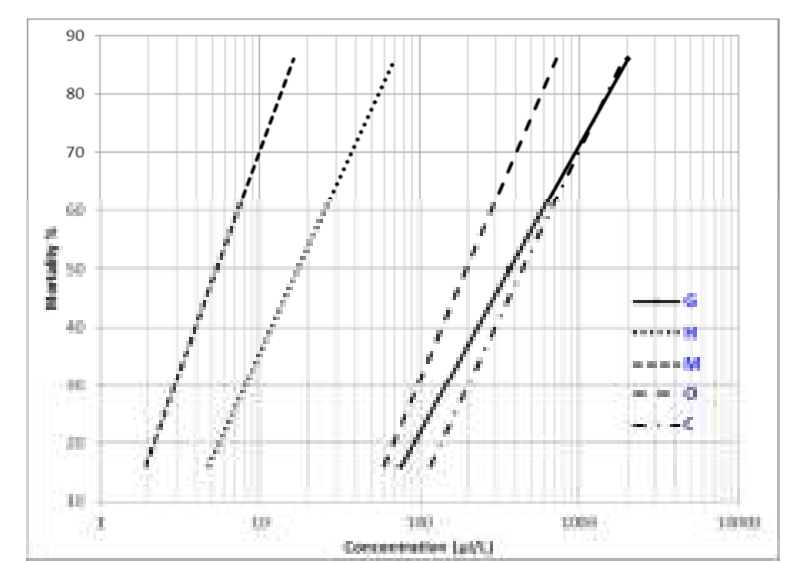

Figure 1. LC-p lines of certain insecticides against the full grown larvae of $B$. zonata in sand.

$\mathrm{G}=$ Glory 5\%, $\mathrm{H}=$ Heater 3\%, $\mathrm{M}=$ Marisol 1.8\%, $\mathrm{O}=$ Opal 5\%, $\mathrm{C}=\mathrm{Cymax}$ 5\%

Toxicity against $C$. capitata

As shown in Table (2) and Fig. (2), Opal 5\%EC was the most effective insecticide on the $3^{\text {rd }}$ larval instar of C. capitata showing the lowest value of $\mathrm{LC}_{50}$ of 11.299 $\mu \mathrm{1} / \mathrm{L}$ followed by Cymax $5 \% \mathrm{EC}$, Glory $5 \% \mathrm{EC}$, Marisol $1.8 \% \mathrm{EC}$ and Heater $3 \% \mathrm{SC}$ which recorded $\mathrm{LC}_{50}$ values of $12.235,17.455,75.643$ and $134.304 \mu 1 / L$, respectively. On 
the other hand, with regard to $\mathrm{LC}_{90}$ values, Cymax $5 \% \mathrm{EC}$ was much more the toxic followed descendingly by Opal 5\%EC, Marisol 1.8\%EC, Glory 5\%EC and Heater 3\% SC. The respective $\mathrm{LC}_{90}$ values were $48.611,142.566,169.442$, 226.498 and $548.548 \mu \mathrm{l} / \mathrm{L}$. Respecting slope values, Marisol 1.8\%EC showed the steepest toxicity line (3.660), but that of Opal 5\%EC was the flattest one (1.164). The toxicity of the used insecticides (at $\mathrm{LC}_{50}$ ) was $64.73,8.41$, 14.94 and $92.35 \%$ of the standard compound (Opal5\%EC) for Glory $5 \% \mathrm{EC}$, Heater $3 \% \mathrm{SC}$, Marisol $1.8 \% \mathrm{EC}$ and Cymax 5\%EC, respectively. But, at $\mathrm{LC}_{90}$ Cymax 5\%EC was the standard, where toxicity of the other tested compounds was $21.46,8.86,28.69$ and $34.10 \%$ of the standard one for Glory $5 \% \mathrm{EC}$, Heater $3 \% \mathrm{SC}$, Marisol $1.8 \% \mathrm{EC}$ and Opal 5\%EC, successively.

Table 2. Toxicity of certain insecticides against the full grown larvae of $C$. capitata in sand.

\begin{tabular}{lccccc}
\hline \multirow{2}{*}{ Compound } & \multirow{2}{\mathbf{LC}_{\mathbf{50}}}{} & \multirow{2}{*}{$\begin{array}{c}\mathbf{L C}_{\mathbf{9 0}} \\
(\boldsymbol{\mu} / \mathbf{L})\end{array}$} & $\boldsymbol{( \mu \mathbf { l } / \mathbf { L } )}$ & Slope & \multicolumn{2}{c}{$\begin{array}{c}\text { Toxicity } \\
\text { index at }\end{array}$} \\
\cline { 5 - 7 } & & & & $\mathbf{L C}_{\mathbf{5 0}}$ & $\mathbf{L C}_{\mathbf{9 0}}$ \\
\hline Cymax 5\%EC & 12.235 & 48.611 & $2.139 \pm 0.362$ & 92.35 & 100 \\
Glory 5\%EC & 17.455 & 226.498 & $1.151 \pm 0.160$ & 64.73 & 21.46 \\
Heater 3\%SC & 134.304 & 548.548 & $2.097 \pm 0.400$ & 8.41 & 8.86 \\
Marisol 1.8\%EC & 75.643 & 169.442 & $3.659 \pm 0.534$ & 14.94 & 28.69 \\
Opal 5\%EC & 11.299 & 142.566 & $1.164 \pm 0.209$ & 100 & 34.10 \\
\hline
\end{tabular}

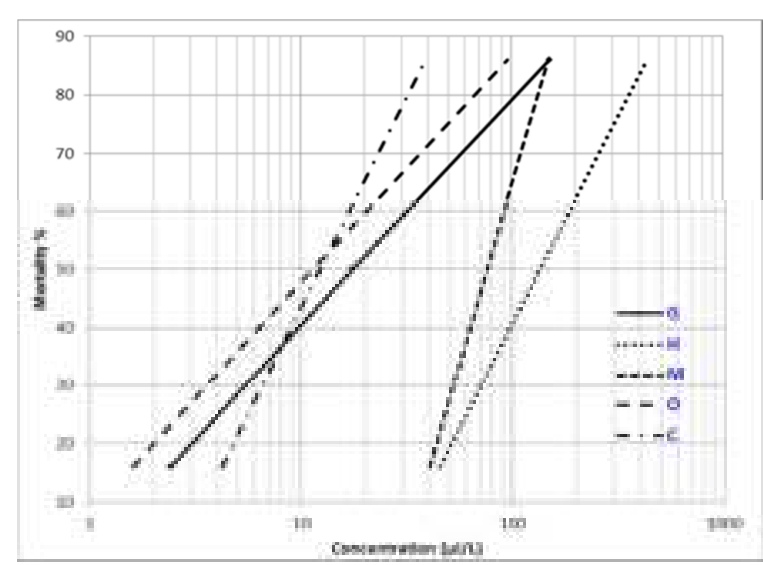

Figure 2. LC-p lines of certain insecticides against the full grown larvae of $\boldsymbol{C}$. capitata in sand.

$\mathrm{G}=$ Glory 5\%, H= Heater 3\%, M= Marisol 1.8\%, $\mathrm{O}=$ Opal 5\%, $\mathrm{C}=\mathrm{Cymax} \mathbf{5 \%}$

\section{2- Toxicity Against the 3-Day Old Pupae}

\section{Toxicity against $B$. zonata}

Results compiled in Table (3) and Fig. (3) indicate the toxicity of the tested insecticides against $B$. zonata three-day old pupae in sand. The obtained results revealed that Marisol $1.8 \% \mathrm{EC}$ was the most potent compound at both $\mathrm{LC}_{50}$ and $\mathrm{LC}_{90} \quad(395.461$ and $819.698 \mu \mathrm{l} / \mathrm{L}$, respectively) surpassing the other used insecticides. Cymax $5 \% \mathrm{EC}$ and Opal 5\% EC alternated the second and third orders at $\mathrm{LC}_{50}$ and $\mathrm{LC}_{90}$, respectively. The efficiency of both Glory 5\%EC and Heater 3\% SC was much more lower than that of the abovementioned three compounds recording high values of both $\mathrm{LC}_{50}$ and $\mathrm{LC}_{90}$ against the 3day old pupae of $B$. zonata of $2706.538,25754.403$ and $7983.618,185422.0 \mu \mathrm{l} / \mathrm{L}$, successively. Slope values of toxicity lines of the five used compounds were 4.049, 2.728, 2.259, 1.768 and 1.495 for Marisol 1.8\%EC, Glory 5\%EC, Opal 5\%EC Cymax 5\%EC and Heater 3\%SC, respectively. Marisol 1.8\%EC had the steepest LC-p line, whereas Heater $3 \% \mathrm{SC}$ had the flattest one. The efficiency of the used insecticides was differently varied, where Marisol $1.8 \% \mathrm{EC}$ was the standard at both $\mathrm{LC}_{50}$ and $\mathrm{LC}_{90}$. The potency of the other pesticides was $64.23,58.51,14.61$ and $1.54 \%$ of the standard compound for Cymax $5 \% \mathrm{EC}$, Opal 5\%EC, Glory 5\%EC and Heater $3 \% \mathrm{SC}$, successively. The arrangement at $\mathrm{LC}_{90}$ was Opal 5\%EC, Cymax 5\%EC, Glory 5\%EC and Heater 3\%SC by 32.85, 25.07, 10.27 and $0.44 \%$ of Marisol $1.8 \%$, respectively.

Table 3. Toxicity of certain insecticides against the 3day old pupae of $B$. zonata in sand.

\begin{tabular}{lcccccc}
\hline \multirow{2}{*}{ Compound } & \multirow{2}{*}{$\begin{array}{c}\mathbf{L C}_{\mathbf{5 0}} \\
(\boldsymbol{\mu l} / \mathbf{L})\end{array}$} & $\begin{array}{c}\mathbf{L C}_{\mathbf{9 0}} \\
(\boldsymbol{\mu l} / \mathbf{L})\end{array}$ & Slope & \multicolumn{3}{c}{$\begin{array}{c}\text { Toxicity } \\
\text { index at }\end{array}$} \\
\cline { 5 - 7 } & & & & $\mathbf{L C}_{\mathbf{5 0}}$ & $\mathbf{L} \mathbf{C}_{\mathbf{9 0}}$ \\
\hline Cymax 5\%EC & 615.724 & 3269.127 & $1.768 \pm 0.163$ & 64.23 & 25.07 \\
Glory 5\%EC & 2706.538 & 7983.618 & $2.728 \pm 0.703$ & 14.61 & 10.27 \\
Heater 3\%SC & 25754.403 & 185422.0 & $1.495 \pm 0.291$ & 1.54 & 0.44 \\
Marisol1.8\%EC & 395.461 & 819.698 & $4.049 \pm 0.893$ & 100 & 100 \\
Opal 5\%EC & 675.893 & 2495.406 & $2.259 \pm 0.705$ & 58.51 & 32.85 \\
\hline
\end{tabular}

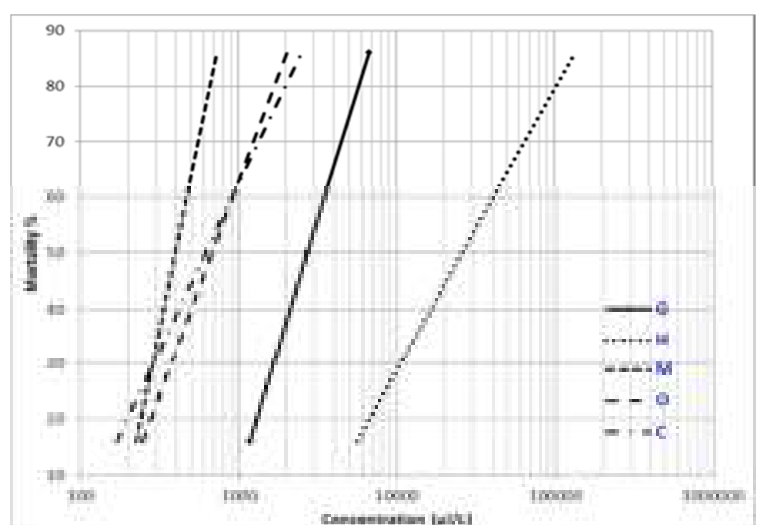

Figure 3. LC-p lines of certain insecticides against the 3-day old pupae of $B$. zonata in sand.

$\mathrm{G}=$ Glory 5\%, H= Heater 3\%, M= Marisol $1.8 \%, O=$ Opal 5\%, $\mathrm{C}=$ Cymax $5 \%$

Toxicity against $C$. capitata

As shown in Table (4) and Fig. (4), efficacy of the tested insecticides against the 3-day old pupae of $C$. capitata differently varied. Marisol1.8\%EC was the most efficient showing the lowest values of both $\mathrm{LC}_{50}(151.373$ $\mu \mathrm{l} / \mathrm{L})$ and $\mathrm{LC}_{90}(354.051 \mu \mathrm{l} / \mathrm{L})$, whereas Heater $3 \% \mathrm{SC}$ was the lowest potent recording the highest values of both $\mathrm{LC}_{50}$ and $\mathrm{LC}_{90}(30274.894$ and $243203.0 \mu \mathrm{l} / \mathrm{L}$, respectively). At $\mathrm{LC}_{50}$, the other used insecticides descendingly arranged as Cymax 5\%EC (329.399 $\mu \mathrm{l} / \mathrm{L})$, Glory 5\%EC (488.851 $\mu \mathrm{l} / \mathrm{L})$ and Opal $5 \% \mathrm{EC}(775.450 \mu \mathrm{l} / \mathrm{L})$. But, at $\mathrm{LC}_{90}$ they were arranged as Glory 5\% EC $(962.476 \mu \mathrm{l} / \mathrm{L})$, Cymax $5 \% \mathrm{EC}(995.582 \mu \mathrm{l} / \mathrm{L})$ and Opal 5\%EC (1353.306 $\mu \mathrm{l} / \mathrm{L})$. Slope values of LC-p line of the used compounds descendingly were 1.416, 2.668, 3.473, 4.356 and 5.300 for Heater $3 \% \mathrm{SC}$ (the flattest line), Cymax 5\%EC, Marisol $1.8 \% \mathrm{EC}$, Glory $5 \% \mathrm{EC}$ and Opal 5\%EC (the steepest toxicity line). Considering Marisol $1.8 \% \mathrm{EC}$ the standard compound, the efficacy of the others against 3-day old pupae of $C$. capitata differently varied, the toxicity of the tested compounds was more lower than the standard at both $\mathrm{LC}_{50}$ and $\mathrm{LC}_{90}$ by $30.97,36.79 ; 0.50,0.15 ; 19.52$, 26.16 and $45.95,35.56 \%$ of the Marisol $1.8 \% \mathrm{EC}$ (the standard) for Glory $5 \% \mathrm{EC}$, Heater $3 \% \mathrm{SC}$, Opal $5 \% \mathrm{EC}$ and Cymax 5\%EC, respectively.

\section{2- Comparative Toxicity Against Larvae}

Data compiled in Table (5) comparatively show the effect of the used compounds against the third larval instar 
of both B. zonata and C. capitata which more differently varied at $\mathrm{LC}_{50}$ and $\mathrm{LC}_{90}$ values. The full grown larvae of $B$. zonata were the most susceptible to Heater $3 \% \mathrm{SC}$ and Marisol $1.8 \% \mathrm{EC}$ at both $\mathrm{LC}_{50}$ and $\mathrm{LC}_{90}$, where those of $C$. capitata showed tolerance level to the two insecticides by 7.78, 14.16 and 6.02, 8.47 fold at $\mathrm{LC}_{50}$ and $\mathrm{LC}_{90}$, respectively. On the other side, the $3^{\text {rd }}$ larval instar of $B$. zonata were more susceptible than that of $C$. capitata which showed differently level of tolerance to Glory $5 \% \mathrm{EC}$, Opal $5 \% \mathrm{EC}$ and Cymax $5 \% \mathrm{EC}$ by $21.12,17.43$, 36.27 and $12.32,6.45,51.34$ fold at $\mathrm{LC}_{50}$ and $\mathrm{LC}_{90}$, respectively.

Table 4. Toxicity of certain insecticides against the 3day old pupae of $C$. capitata in sand.

\begin{tabular}{lccccc}
\hline Compound & $\begin{array}{c}\mathbf{L C}_{\mathbf{5 0}} \\
(\boldsymbol{\mu l} / \mathbf{L})\end{array}$ & $\begin{array}{c}\mathbf{L C}_{\mathbf{9 0}} \\
(\boldsymbol{\mu} \mathbf{l} / \mathbf{L})\end{array}$ & Slope & \multicolumn{2}{c}{$\begin{array}{c}\text { Toxicity } \\
\text { index at }\end{array}$} \\
\hline Cymax 5\%EC & 329.399 & 995.582 & $2.668 \pm 0.372$ & 45.95 & 35.56 \\
Glory 5\%EC & 488.851 & 962.476 & $4.356 \pm 0.471$ & 30.97 & 36.79 \\
Heater 3\%SC & 30274.894 & 243203.0 & $1.416 \pm 0.107$ & 0.5 & 0.15 \\
Marisol1.8\%EC & 151.373 & 354.051 & $3.473 \pm 0.219$ & 100 & 100 \\
Opal 5\%EC & 775.450 & 1353.306 & $5.300 \pm 0.437$ & 19.52 & 26.16 \\
\hline
\end{tabular}

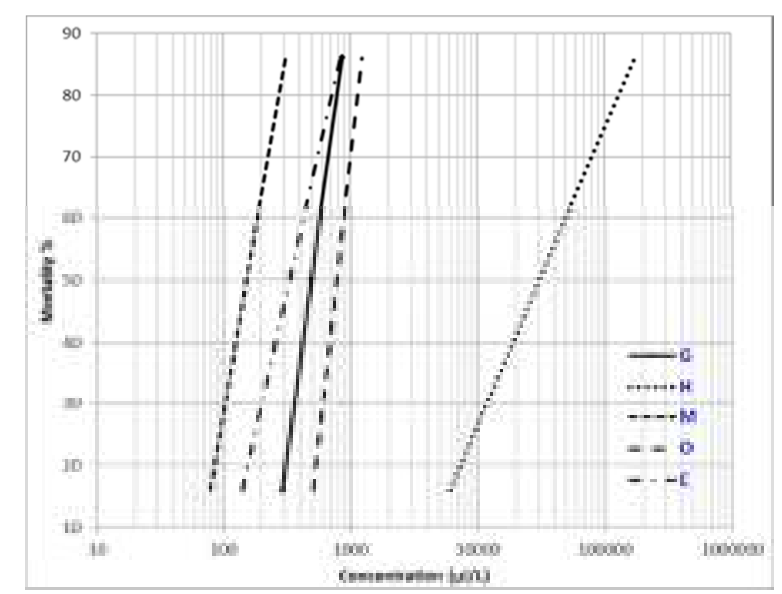

Figure 4. LC-p lines of certain insecticides against the 3-day old pupae of $C$. capitata in sand.

G= Glory 5\%, H= Heater 3\%, M= Marisol 1.8\%, O= Opal 5\%, $\mathrm{C}=\operatorname{Cymax} \mathbf{5 \%}$

Table 5. Comparative toxicity of certain insecticides against the full grown larvae of both Bactrocera zonata and Ceratitis capitata in sand under laboratory conditions.

\begin{tabular}{lccccccccc}
\hline \multirow{2}{*}{ Compound } & \multicolumn{2}{c}{$\mathbf{L C}_{\mathbf{5 0}}(\boldsymbol{\mu} \mathrm{l} / \mathrm{L})$} & \multicolumn{2}{c}{ Fold } & \multicolumn{2}{c}{$\mathbf{L C}_{\mathbf{9 0}}(\boldsymbol{\mu l} / \mathbf{L})$} & \multicolumn{2}{c}{ Fold } \\
\cline { 2 - 9 } & B. zonata & C. capitata & B. zonata & C. capitata & B. zonata & C. capitata & B. zonata & C. capitata \\
\hline Cymax 5\%EC & 443.796 & 12.235 & 36.27 & 1 & 2495.620 & 48.611 & 51.34 & 1 \\
Glory 5\%EC & 368.719 & 17.455 & 21.12 & 1 & 2790.899 & 226.498 & 12.32 & 1 \\
Heater 3\%SC & 17.261 & 134.304 & 1 & 7.78 & 91.046 & 548.548 & 1 & 6.02 \\
Marisol 1.8\%EC & 5.343 & 75.643 & 1 & 14.16 & 20.011 & 169.442 & 1 & 8.47 \\
Opal 5\%EC & 196.999 & 11.300 & 17.43 & 1 & 919.546 & 142.566 & 6.45 & 1 \\
\hline
\end{tabular}

\section{3- Comparative Toxicity Against Pupae}

As shown in Table (6), the response of pupae of 3day old of both B. zonata and C. capitata to Glory $5 \% \mathrm{EC}$, Heater 3\%SC, Marisol 1.8\%EC, Opal 5\%EC and Cymax $5 \%$ EC slightly differed. Pupae of $B$. zonata more tolerable than that of $C$. capitate to Glory $5 \% \mathrm{EC}$, Marisol $1.8 \% \mathrm{EC}$ and Cymax $5 \% \mathrm{EC}$ at $\mathrm{LC}_{50}$ and $\mathrm{LC}_{90}$ by $5.54,2.61,1.87$ and $8.29,2.32,3.28$ fold, respectively. But, the reverse was true in case of Heater $3 \% \mathrm{SC}$ where pupae of $C$. capitata was more tolerable than that of B. zonata by $1.18 \%$ and 1.31 fold at $\mathrm{LC}_{50}$ and $\mathrm{LC}_{90}$, consecutively. In case of Opal $5 \% \mathrm{EC}$, the 3-day old pupae of $B$. zonata was more susceptible at $\mathrm{LC}_{50}$, whereas at $\mathrm{LC}_{90}$ pupae of $C$. capitata showed high susceptibility. The tolerance level of $C$. capitata was 1.14 fold at $\mathrm{LC}_{50}$, but it was 1.84 fold for $B$. zonata at $\mathrm{LC}_{90}$. Generally, pupal stage of the two tested species ( $B$. zonata and $C$. capitata) was much more tolerable to each used compounds than the larval stage.

Table 6. Comparative toxicity of certain insecticides against the three-day old pupae of both Bactrocera zonata and Ceratitis capitata in sand under laboratory conditions.

\begin{tabular}{lccccccccc}
\hline \multirow{2}{*}{ Compound } & \multicolumn{2}{c}{$\mathbf{L C}_{\mathbf{5 0}}(\boldsymbol{\mu l} / \mathbf{L})$} & \multicolumn{3}{c}{ Fold } & \multicolumn{2}{c}{$\mathbf{L C}_{\mathbf{9 0}}(\boldsymbol{\mu} \mathrm{l} / \mathrm{L})$} & \multicolumn{2}{c}{ Fold } \\
\cline { 2 - 9 } & B. zonata & C. capitata & B. zonata & C. capitata & B. zonata & C. capitata & B. zonata & C. capitata \\
\hline Cymax 5\%EC & 615.724 & 329.399 & 1.87 & 1 & 3269.127 & 995.582 & 3.28 & 1 \\
Glory 5\%EC & 2706.538 & 488.851 & 5.54 & 1 & 7983.618 & 962.476 & 8.29 & 1 \\
Heater 3\%SC & 25754.403 & 30274.894 & 1 & 1.18 & 185422.0 & 243203.0 & 1 & 1.31 \\
Marisol 1.8\%EC & 395.461 & 151.373 & 2.61 & 1 & 819.698 & 354.051 & 2.32 & 1 \\
Opal 5\%EC & 675.893 & 775.450 & 1 & 1.14 & 2495.406 & 1353.306 & 1.84 & 1 \\
\hline
\end{tabular}

\section{DISCUSSION AND CONCLUSION}

Toxicity of the same compound differed according to the tested species and the examined stage of the same species. Saul and Seifert (1990) stated that the toxicity of methoprene to Ceratitis capitata, Dacus dorsalis [Bactrocera dorsalis] and D. cucurbitae [B. cucurbitae] was the highest in mature larvae and the newly formed pupae. Four insect growth regulators were tested by Mohamed and El-Nasser (1992) as dips for their toxicity and chemosterilant effects against prepupae and pupae of the tephritid Ceratitis capitata. BAY Sir-8514 [triflumuron] was the most toxic compound against prepupae and pupae, and had a sterilizing effect against both sexes when applied to the pupae. Prepupae were more sensitive than pupae to all the compounds, which included XRD 473 [hexafluron], IKI 7899 [chlorfluazuron] and Dowco 439 [chlorpyrifos-methyl]. Stark et al. (1992) determined effects of cyromazine and diazinon on eclosion, longevity and reproduction of Ceratitis capitata, Bactrocera dorsalis and B. cucurbitae. They found that formation of puparia not affected by cyromazine but affected by diazinon in a concentration-dependent manner 
at the concentrations tested. At $\mathrm{LC}_{50}$ values, B. dorsalis and $B$. cucurbitae were more susceptible to cyromazine than to diazinon; $C$. capitata was equally susceptible to both chemicals. Mosallam (1993) conducted laboratory tests to evaluate efficacy of certain pesticides belonging to different groups against some immature stages of the Mediterranean fruit fly using different methods of applications. The author reported that the toxicity of used pesticides differently varied against the tested immature stages according to type of pesticide and method of application as well as the tested stage (mature larvae and pupae of 3-day old). Purcell and Schroeder (1996) determined, in laboratory, the potency of the organosilicone surfactant Silwet L-77 for 3 species of tephritids (C. capitata, B. dorsalis and B. cucurbitae). The biological activity of Silwet was compared to that of diazinon by exposing puparia of $C$. capitata to sand treated with each chemical within 1 h, 7 days, and 14 days after treatment. Silwet killed C. capitata and B. dorsalis at concentration within the range of field application rates. The response of $B$. cucurbitae was the most variable and very high concentrations were required to kill $>90 \%$ of puparia. A $75 \%$ decrease in mortality of C. capitata puparia occurred 14 days after sand treatment with diazinon. In contrast, Silwet remained as toxic to $C$. capitata puparia at 14 days as on the $1^{\text {st }}$ day of treatment. Abdallahi et al. (2000) conducted laboratory studies to determine the effect of 2 new pesticides viz. fipronil and pyriproxyfen on the fruitfly C. capitata. Larval development and percentage of adult eclosion were affected. Treatment of the medium for pupation with pyriproxyfen affected the larval development. Stark and Vargas (2009) evaluated, in Hawaii, toxicity of Platinum, Force, Admire, Regent, and Warrior after application to sand and soil as drenches for control of the Mediterranean fruit fly, $C$. capitata (Wiedemann); melon fly, B. cucurbitae (Coquillett); and oriental fruit fly, $B$. dorsalis (Hendel) and reported that susceptibility of each species differed. In sand, the order of toxicity at $\mathrm{LC}_{50}$ based on the $95 \%$ confidence limit overlap approach for $C$. capitata from most toxic to least toxic was diazinon $>$ Force $=$ Warrior $>$ Admire $=$ Platinum $>$ Regent. The order of toxicity for $B$. dorsalis was diazinon $>$ Platinum $=$ Warrior $=$ Force $>$ Regent $=$ Admire. The order of toxicity for B. cucurbitae was Warrior = diazinon $>$ Force $=$ Regent $=$ Platinum $=$ Admire . Rizwanual Haq et al. (2012) studied effects of lead acetate, in the concentrations of $0.125 \mathrm{mg}$., $0.25 \mathrm{mg}$., $0.5 \mathrm{mg}, 1.0 \mathrm{mg}$ and $2.0 \mathrm{mg}$ on $B$. dorsalis, B. zonata, at 48 hours posttreatment. It was observed that under the effects of lead abnormalities and malformation were developed in the larvae of flies. Teratomorphic changes were observed as elongated wings, de-shaped wings, elongated and folded legs, changes in melanization of larvae, pupae and adults. Some other structural abnormalities of larvae and pupal shape were also observed. Also, toxicity of certain insecticides belonging to different chemical groups (Beticol, Biosad, Elsan, Lufox, Mani, Match and Radiant) against full grown larvae and pupae of $B$. zonata with different concentrations as contact poisons or in sandy soil treatments were assayed by Halawa et al. (2013) under laboratory conditions. Results showed that Radiant was the most contact toxicant on full grown larvae among the tested insecticides, followed by Elsan, Beticol, Lufox, Match, Biosad and Mani. The respective $\mathrm{LC}_{50}$ values were $4.60,17.13,18.65,34.97,108.24,143.03$ and $286.81 \mu 1 / \mathrm{L}$. On 1-day old pupae, Elsan was the most potent compound followed by Match, Lufox, Beticol, Radiant, Mani and Biosad. But, in sandy soil treatment, Lufox was the most efficient against 1-day old pupae at $\left(\mathrm{LC}_{50}=156.02 \mu \mathrm{l} / \mathrm{L}\right)$. Stark et al. (2014) evaluated the effectiveness of several insecticides as Diazinon replacements for control of three economically important fruit fly species, Mediterranean fruit fly, C. capitata, melon fly, B. cucurbitae, and oriental fruit fly, $B$. dorsalis using a semi-field approach. Pupae of fruit fly species that were ready to eclose within $24 \mathrm{~h}$ were exposed to organic soil treated with Radiant SC (Spinetoram), Force $3 \mathrm{G}$ and Force CS (Tefluthrin); Warrior II (Lambda-cyhalothrin); the biopesticides, Entrust and Entrust SC (Spinosad); GardStar 40\% EC (Permethrin) or Diazinon AG 600. All alternative insecticides resulted in a significant reduction in adult emergence and were not significantly different from Diazinon. Insecticides that resulted in no adult emergence for $C$. capitata and $B$. dorsalis were Entrust SC, Warrior II, GardStar, and Force CS, and for B. cucurbitae, Entrust SC and Force CS. Also, late third instar larvae ready to pupate were exposed to organic soil treated with Force CS, Warrior II, Entrust SC, GardStar, or Diazinon AG 600. All alternative insecticides resulted in a significant reduction in adult emergence and were not significantly different from Diazinon. El-Rahman et al. (2017) tested the two compounds of phloxine B and menadione for toxicity to the peach fruit fly, Bactrocera zonata (Saunders) under both dark and sun light conditions and reported that both compounds had no significant toxic effect in dark and concentration-dependent toxicity when insect exposed to sunlight for $2 \mathrm{hrs}$. Phloxine B was approximately 1000 time more toxic to $B$. zonata than menadione with $\mathrm{LC}_{25}$ in water of $0.0007 \mathrm{~g} \%$ and $0.854 \mathrm{~g} \%$ $(\mathrm{w} / \mathrm{v})$, respectively. Adding menadione to phloxine resulted in significant antagonistic effects on insect mortality, which could be due to menadione alteration of the $\mathrm{pH}$ of the feeding media and/or menadione induction of the ROSdetoxifying enzymes, particularly peroxidase. It is concluded that phloxine $\mathrm{B}$ and menadione are incompatible and their mixture is not likely to pose any significant addition to their control potential against $B$. zonata. Gazit and Akiva (2017) evaluated the toxicity of malathion and spinosad to B. zonata and C. capitata as contact exposure (tactile) or feeding (insecticides mixed with bait). Results showed that doses of 1,000 and 2,000 ppm of malathion were highly toxic to $C$. capitata both upon contact and when eaten with bait, a dose of 10,000 ppm (1\%) caused only 10 to $35 \%$ mortality of $B$. zonata. Khan and Muhammed Naveed (2017) evaluated the effectiveness of a bio-insecticide, emamectin benzoate with other conventionally used insecticides against $B$. zonata. Results revealed high toxicity of emamectin benzoate with $\mathrm{LC}_{50}$ value of 38.25 followed by trichlorfon, lambdacyhalothrin and imidacloprid with $\mathrm{LC}_{50}$ values of 44.21, 58.98 and $187.81 \mathrm{ppm}$, after $24 \mathrm{~h}$ post-treatment, respectively. It is be conclude that the efficacy of a compound itself differs from one species to another. Also, the susceptibility of the different stages within the same species differs to the same compound. 


\section{REFERENCES}

Abbott, W.S. (1925). A method of computing the effectiveness of an insecticide. J. Econ. Entomol., 18(2): 265-267.

Abdallahi, E.; Adan, A. and Vinuela, E. (2000). Toxicity of pyriproxyfen and fipronil on Opius concolor Szepligeti (Hymenoptera: Braconidae) and Ceratitis capitata (Wiedemann) (Diptera: Tephritidae). Boletin de Sanidad Vegetal, Plagas, 26(4): 503-511. [Spanish]

Drew, R.A.I. (1989). The tropical fruit flies (Diptera: Tephritidae: Dacinae) of the Australian and Oceanian regions. Memoris of Queensland Museum, 26: p.T- 521.

El-Rahman, M.M.A.; Azazy, A.M. and El-Hefny, A.A. (2017). Toxicity of the photoactive compounds phloxine $\mathrm{B}$ and menadione on Bactrocera zonata (Diptera: Tephritidae). Egyptian J. Agric. Res., 95(3): 1053-1067.

FAO/IAEA (Food and Agriculture Organization/ International Atomic Energy Agency) (2000). Peach fruit fly, Bactrocera zonata (Saunders). Joint FAO/IAEA Duvision, Vienna, 50 pp.

Finney, D.J. (1952). Probit analysis statistical treatment of the sigmoid response curve. Cambridge Univ. Press, Cambridge.

Gazit, Y. and Akiva, R. (2017). Toxicity of malathion and spinosad to Bactrocera zonata and Ceratitis capitata (Diptera: Tephritidae). Florida Entomologist, 100(2): 385-389.

Halawa, S.M.; R.A.A. El-Hosary; A.M.Z. Mosallam; E.F. El-Khayat and M.M.S. Ismail (2013). Toxicological, biological and biochemical effects of certain insecticides on Bactrocera zonata (Saunders) (Diptera, Tephritidae). AmericanEurasian J. Toxicol. Sci. (AEJTS), 5(3): 55-65.

Jilani, Ghulam; M.K. Khattak and Faisal Shahzad (2006). Toxic and growth regulating effect of ethanol extract and petroleum ether extract of Valariana officianalis L. against Bactrocera zonata Saunder. Pakistan Entomologist, 28(1): 11-14.

Khan, R.A. and Muhammed Naveed (2017). Evaluation of comparative toxicity of different insecticides against fruit fly, Bactrocera zonata Saunders (Diptera: Tephritidae). Pakistan J. Zool., 49(1):399401.

Lysandrou, M. (2009). Fruit flies in the Mediterranean and Arab world: How serious a threat is they how can we minimize their impact. Arab J. Plant Prot., 27: 236-239.
McDonald, P.T. (1986). Larger egg clutches following host deprivation in colonized Ceratitis capitata (Diptera: Tephrtidae). J. Econ. Entomol., 79(2): 392-394.

Mohamed, S.H. and El-Nasser, M.A.A. (1992). Toxicity and sterilizing effects of certain benzoylphenyl urea compounds against Mediterranean fruit fly Ceratitis capitata (Wied.). Assiut J. Agric. Sci., 23(4): 285292.

Mosallam, A.M.Z. (1993). Studies on the Mediterranean fruit fly, Ceratitis capitata (Wied.) and its control. M.Sc. Thesis, Fac. Agric., Zagazig Univ., 187 pp.

Purcell, M.F. and Schroeder, W.J. (1996). Effect of Silwet L-77 and diazinon on three tephritid fruit flies (Diptera: Tephritidae) and associated endoparasitoids. J. Econ. Entomol., 89(6): 15661570.

Rizwanual, Haq; Khan, M.F. and Ehteshamul, Haq (2012). Teratogenic effect of lead acetate on Bactrocera dorsalis and Bactrocera zonata. Pakistan J. Pharma. Sci., 25(2): 323-332.

Saul, S. and Seifert, J. (1990). Methoprene on papayas: persistence and toxicity to different developmental stages of fruit flies (Diptera: Tephritidae). J. Econ. Entomol., 83(3): 901-904.

Shehata, N.F., Younes, M.W.F. and Mahmoud, Y.A. (2006). Anatomical effects of gamma irradiation on the peach fruit fly, Bactrocera zonata (Saund.) male gonads. J. Appl. Sci. Res., 2 (8): 510-513.

Stark, J.D. and Vargas, R. (2009). An evaluation of alternative insecticides to diazinon for control of tephritid fruit flies (Diptera: Tephritidae) in soil. J. Econ. Entomol., 102(1): 139-143.

Stark, J.D.; Vargas, R.I.; Messing, R.H. and Purcell, M. (1992). Effects of cyromazine and diazinon on three economically important Hawaiian tephritid fruit flies (Diptera: Tephritidae) and their endoparasitoids (Hymenoptera: Braconidae). J. Econ. Entomol., 85(5): 1687-1694.

Stark, J.D.; Vargas, R.I.; Souder, S.K.; Fox, A.J.; Smith, T.R.; Leblanc, L. and Mackey, B. (2014). Simulated field applications of insecticide soil drenches for control of tephritid fruit flies. Biopesticides International, 10(2): 136-142.

Sun, Y.P. (1950). Toxicity index- An improved method of comparing the relative toxicity of insecticides. J. Econ. Entomol., 43(1): 45-53.

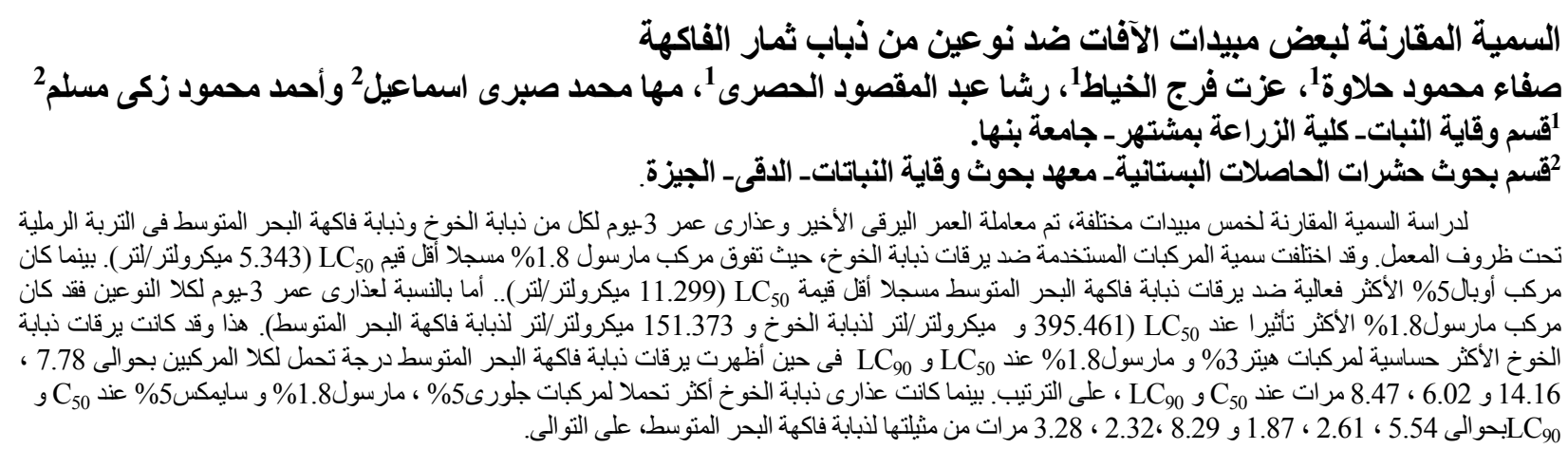

